\title{
Development of gastric dysplasia in pernicious anaemia: a clinical and endoscopic follow up study of 80 patients
}

\author{
U Armbrecht, R W Stockbrügger, J Rode, G G Menon, P B Cotton
}

\begin{abstract}
The development of gastric dysplasia and neoplasia in patients with pernicious anaemia has been evaluated in a prospective clinical and endoscopic follow up study. After initial screening of 80 patients between 1978 and 1980 , one patient underwent total gastrectomy for a gastric malignancy and 12 were kept under surveillance and underwent endoscopy at a mean interval of 14 months. In the remaining 67 patients further investigation was attempted six to seven years after the initial investigation. The continuous follow up study identified carcinoids in one patient and an adenoma with severe dysplasia in a further patient. The grade and site of mucosal dysplasia differed from one investigation to the next, but no overall progression was observed. Of the 79 patients, eight had died by the time of the reinvestigation, two of unknown cause and six of causes unrelated to pernicious anaemia. In 38 of the remaining 71 patients, clinical data only were available, with no evidence of new gastric malignancy. In 27 patients it was possible to perform an upper gastrointestinal endoscopy, when no change in the degree of dysplasia was detected. In six patients no follow up information was obtainable. In conclusion, patients with pernicious anaemia should be investigated by upper gastrointestinal endoscopy soon after diagnosis. Polyps should be removed wherever possible. In the presence of severe mucosal dysplasia or polyps that are not removed, frequent reinvestigation should be performed, provided the patient is eligible for gastric surgery. In the remaining patients, follow up endoscopies at about five year intervals would seem sufficient.
\end{abstract}

Because a close association has been described between atrophic gastritis and intestinal metaplasia and the development of gastric carcinoma, ${ }^{1-5}$ these are now considered to be precancerous lesions. ${ }^{6}$ In pernicious anaemia, chronic atrophic gastritis with intestinal metaplasia is common, and gastric polyps are frequently found..$^{7-10}$ Endoscopic screening of patients with this disorder showed a high incidence of gastric mucosal dysplasia, ${ }^{910}$ and pernicious anaemia is therefore assumed to be a precancerous condition.

Although a number of previous studies ${ }^{112}$ may have overestimated the prevalence of gastric cancer in pernicious anaemia, a recent investigation $^{5}$ also points to a threefold increase in the risk of gastric malignancy. The benefit of preventive endoscopic screening in patients with pernicious anaemia is, however, still controversial..$^{4-9} 1213 \mathrm{In}$ view of the prevalence of the disorder (about $1 / 1000$ in Western countries), a continuing gastric screening programme of these patients would consume considerable medical economic, and administrative resources. ${ }^{1014}$

Between 1978 and 1980 Stockbrügger et al undertook gastroscopic screening for gastric dysplasia and neoplasia in 80 patients with proved pernicious anaemia from nine London hospitals. ${ }^{9}$ The present study is a prospective clinical and endosconic follow up investigation of the initial screening study. Its purpose was to elucidate the natural history of gastric dysplasia and neoplasia in pernicious anaemia and to determine whether gastroscopic monitoring of patients with this premalignant condition should be recommended.

\section{Investigations}

\section{PATIENTS}

Twelve patients (seven women and five men), aged 20 to 75 years (median 49 years) at the initial investigation, were endoscoped at regular intervals between June 1980 and August 1985. They all felt well, were interested in the follow up investigations, and had good geographical access to the Middlesex Hospital.

Severe dysplasia in a polyp had been diagnosed in one, moderate mucosal dysplasia in two, and mild dysplasia in five patients. In the remaining four patients there was no evidence of mucosal dysplasia at the initial screening examination, but in two endocrine cell proliferations had been found in the oxyntic mucosa, with multiple polyps in one.

Between September 1985 and February 1986 that is, six to seven years after the initial screening - an attempt was made to reinvestigate all the original patients, including the 12 mentioned above. One of the 80 patients was excluded, however, as she had had a total gastrectomy for the early gastric carcinoma found at the first screening. The data for the remaining 79 patients ( 35 women, 44 men; aged 20 to 79 years (median 63 years at the first investigation) were reviewed. In 1978-80 severe dysplasia had been found in three, moderate dysplasia in six, mild dysplasia in 24 , and no evidence of dysplasia in 46 patients. Polypoid lesions (including one adenoma with severe dysplasia, and the patient with multiple polypoid carcinoid tumours) had been found in 18 patients. 


\section{METHODS}

The 12 patients undergoing regular follow up were seen repeatedly by the investigators involved in the initial study. Histories of clinical symptoms were taken and upper gastrointestinal endoscopies were performed at a mean interval of 14 months. At every endoscopy, at least three biopsy specimens each were obtained from the gastric mid-body, the prepyloric antrum, the second part of the duodenum, and from all visible lesions. In addition, biopsy specimens were taken for electron microscopy and for immunohistological studies (these latter have been reported separately). ${ }^{\text {is }}$

In 1985-6 the general practitioner or consultant physician, or both, of all 79 patients was approached with a questionnaire to update our information. With the permission of the general practitioner or consultant physician, current hospital notes or necropsy reports, or both, were scrutinised. Live patients were contacted by letter. An interview and upper gastrointestinal endoscopy with biopsy were proposed to those patients considered to be fit and well. Those judged too frail for an endoscopy were interviewed at home by a research nurse. If the interview was refused, the patient was asked to complete a questionnaire on, for example, gastrointestinal symptoms, investigations, treatments, hospital attendances relating to the period after the first screening endoscopy, and on present symptoms and treatments.

\section{ENDOSCOPY AND HISTOLOGY}

Upper gastrointestinal endoscopy was performed as an outpatient procedure as described above. Endoscopic biopsy specimens were routinely fixed in formalin, paraffin processed, and orientated embedded. At least 20 consecutive $5 \mu \mathrm{m}$ sections were cut from each tissue block. The first and last sections were stained with haematoxylin and eosin. The intervening sections were kept for special histochemical and immunohistochemical studies.

The histological material was first assessed independently by two pathologists (JR and GM), one of whom (GM) had made the histological diagnosis in the initial study. Both had access to the original material from the $1978-80$ period. In the few cases in which opinion differed, a unanimous diagnosis and classification of dysplasia and neoplasia was achieved after joint analysis of the specimens. A systematic study of observer variation was not planned as one of the pathologists (GM) might have been biased by his knowledge of the previous findings.

Mucosal dysplasia was defined in accordance with standard criteria into three classes: no $=0$, mild $=1$, moderate $=2$, and severe $=3 .{ }^{16-18}$

\section{Results}

CONTINUING FOLLOW UP 1978-1985 (FIG 1)

Of the 12 patients followed up with repeated endoscopies, one died of a myocardial infarction four and a half years after the initial investigation. Another patient (No 20), who underwent cardiac bypass surgery five years after the first investigation, was put on anticoagulation treatment, and was therefore not followed up with biopsies and histological studies. In this patient, the endoscopic follow up examination performed after seven years showed no macroscopic abnormalities.

Mucosal dysplasia. As can be seen in Figure 1 there was wide intraindividual variation in the grade and site of dysplasia found during the period of observation. A comparison of the mean of the first dysplasia score with that of the last showed no overall increase in the grade of
Figure 1: Non-polypous mucosal dysplasia in 12 patients followed by repeat upper gastrointestinal endoscopies. On the vertical axis the grade of dysplasia is indicated $(\mathrm{se}=$ severe, $m o=$ moderate, $m i=$ mild, $n o=$ none), on the horizontal axis the sequence of endoscopies is given. $\square=$ investigation performed. =site: antrum. $\mathbb{N}=$ site: body. $=$ site: body and antrum.

$\star=$ Anticoagulation treatment initiated, no further biopsy specimens taken. $\star \star=$ Histology necropsy material.
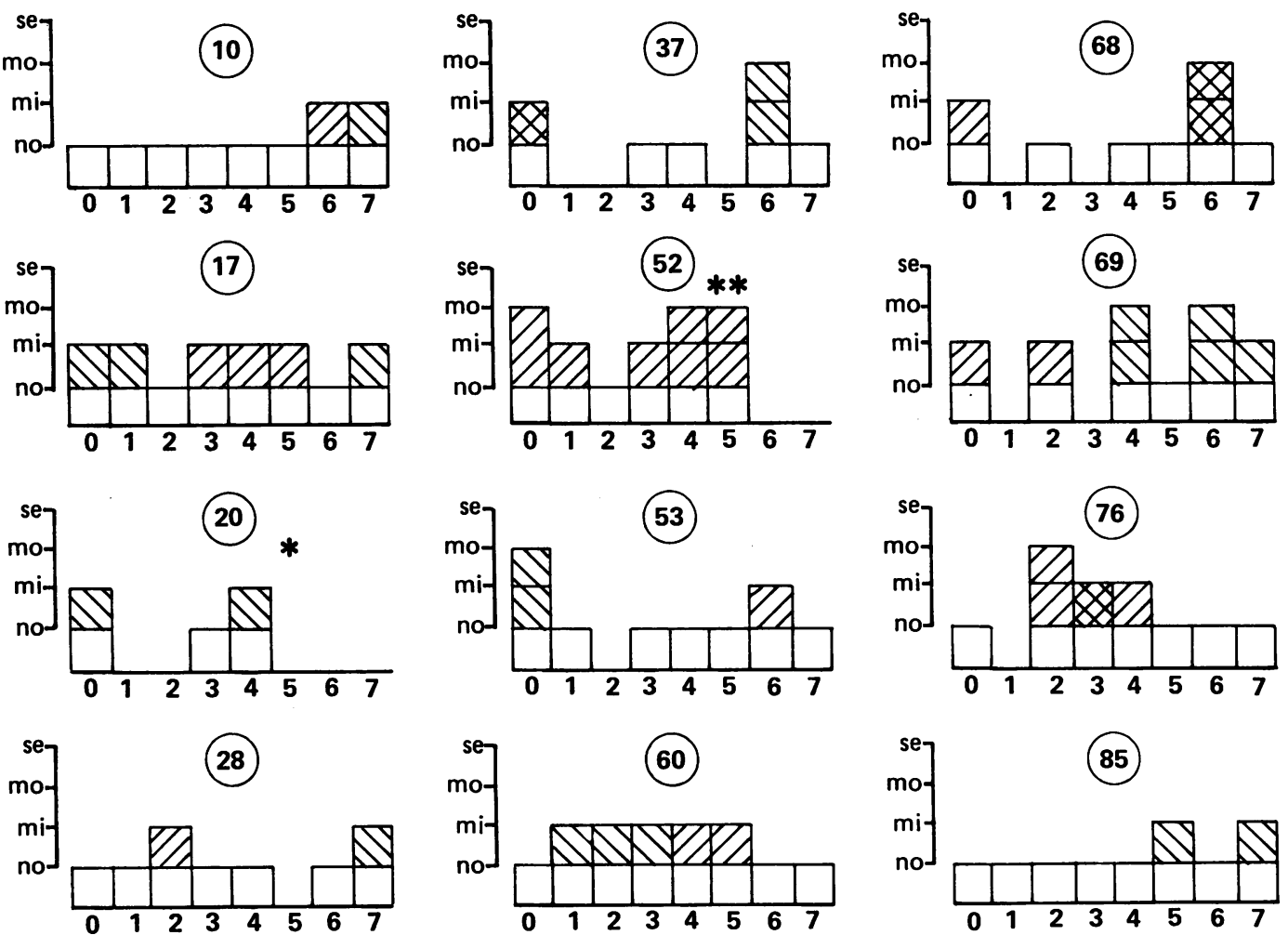
TABLE I Polypoid lesions in 12 patients with pernicious anaemia at the initial investigation and during a follow up period of seven years (number, site, and histological type)

\begin{tabular}{|c|c|c|c|c|c|c|c|c|}
\hline \multirow{2}{*}{$\begin{array}{l}\text { Patient } \\
\text { No }\end{array}$} & \multicolumn{8}{|c|}{ Year of follow up } \\
\hline & 0 & 1 & 2 & 3 & 4 & 5 & 6 & 7 \\
\hline $\begin{array}{l}10 \\
17\end{array}$ & $\begin{array}{l}\text { np }_{1 \mathrm{Rb}(0)} \\
\mathbf{I A b}(3)^{\star}\end{array}$ & $\begin{array}{l}\text { nd } \\
4 \mathrm{Rb}(0)\end{array}$ & $\mathrm{np}_{2 \mathrm{Rb}(0)}$ & $\underset{2 \mathrm{Rb}(0)}{\mathrm{nd}}$ & $\begin{array}{l}\text { np } \\
\text { np }\end{array}$ & $\begin{array}{l}\text { nd } \\
\text { np }\end{array}$ & $\mathrm{np}_{3 \mathrm{Rb}(1)}$ & $\mathrm{np}_{2 \mathrm{Rb}(0)}$ \\
\hline $\begin{array}{l}20 \\
28 \dagger \\
37 \\
52\end{array}$ & $\begin{array}{c}\text { np } \\
>50 \mathrm{Cb}(0) \\
\mathrm{np} \\
\mathrm{np}\end{array}$ & $\begin{array}{c}\text { nd } \\
>50 \mathrm{Cb}(0) \\
\text { nd } \\
\text { np }\end{array}$ & $\begin{array}{c}\text { np } \\
>50 \mathrm{Cb}(0) \\
\text { nd } \\
\text { np }\end{array}$ & $\begin{array}{c}\text { np } \\
>50 \mathrm{Cb}(0) \\
1 \mathrm{Ra}(0) \\
\mathrm{np}\end{array}$ & $\begin{array}{l}\text { nd } \\
>50 \mathrm{Cb}(0) \\
\quad 1 \mathrm{Aa}(0)\end{array}$ & $\begin{array}{l}\text { nd } \\
>50 \mathrm{Cb}(0) \\
\quad 1 \mathrm{Aa}(3)\end{array}$ & $\begin{array}{l}\text { nd } \\
>50 \mathrm{Cb}(0) \\
\quad 1 \mathrm{Aa}(3)\end{array}$ & $\begin{array}{r}\mathrm{np}_{>} \\
\quad \mathrm{Cba}(0) \\
\quad 1 \mathrm{Aa}(3)\end{array}$ \\
\hline 53 & np & nd & np & np & np & np & np & $\mathrm{np}$ \\
\hline 60 & $\mathrm{np}$ & $\mathrm{np}$ & np & $\mathrm{np}$ & $\mathrm{np}$ & np & $\mathbf{I R b}(0)$ & $\mathrm{np}$ \\
\hline 68 & np & nd & np & nd & np & np & np & $\mathrm{np}$ \\
\hline 69 & $\mathrm{np}$ & nd & np & nd & $\mathrm{np}$ & $\mathrm{np}$ & $\mathrm{np}$ & $\mathrm{np}$ \\
\hline 76 & np & nd & np & np & & & np & np \\
\hline 85 & $\mathrm{np}$ & $\mathrm{np}$ & $4 \mathrm{Cb}(0)$ & $4 \mathrm{Cb}(0)$ & $5 \mathrm{Cb}(0)$ & $1 \mathrm{lCb}(0) \ddagger$ & $\mathrm{ICb}(0)$ & $\mathrm{np}$ \\
\hline
\end{tabular}

nd = no endoscopy performed; $\mathrm{np}=$ no polyps found; $\mathrm{A}=$ adenoma, $\mathrm{R}=$ regenerative polyp, $\mathrm{C}=$ carcinoid; $\mathrm{a}=$ gastric antrum, $\mathrm{b}=$ gastric body; in brackets, grade of dysplasia $(0=$ no dysplasia. $1=$ mild, $2=$ moderate, $3=$ severe $)$. ${ }^{\star}$ Polypectomy performed. + Biopsy specimens taken from the six largest polyps at each endoscopy. $¥$ At this follow up investigation biopsy specimens taken from the six largest polyps. schedule of a six to seven year clinical and endoscopic follow up of 80 patients with pernicious anaemia.
Figure 2: Investigation

dysplasia $(0.75 v 0.50)$. The patient who died four and a half years after the initial investigation showed focal adenomatous changes with moderate dysplasia of the gastric antral mucosa at the necropsy examination. Upper gastrointestinal endoscopy four months before death had shown antral ulceration with moderate dysplasia.

Polyps in patients undergoing repeated examinations (Table I). Polypoid lesions were seen in the gastric body in four patients and in the gastric antrum in one. Histological examination showed that these lesions were adenomas, carcinoids, and regenerative polyps. The nature of the polyps varied during the follow up period: patient 17 had had an adenoma with severe

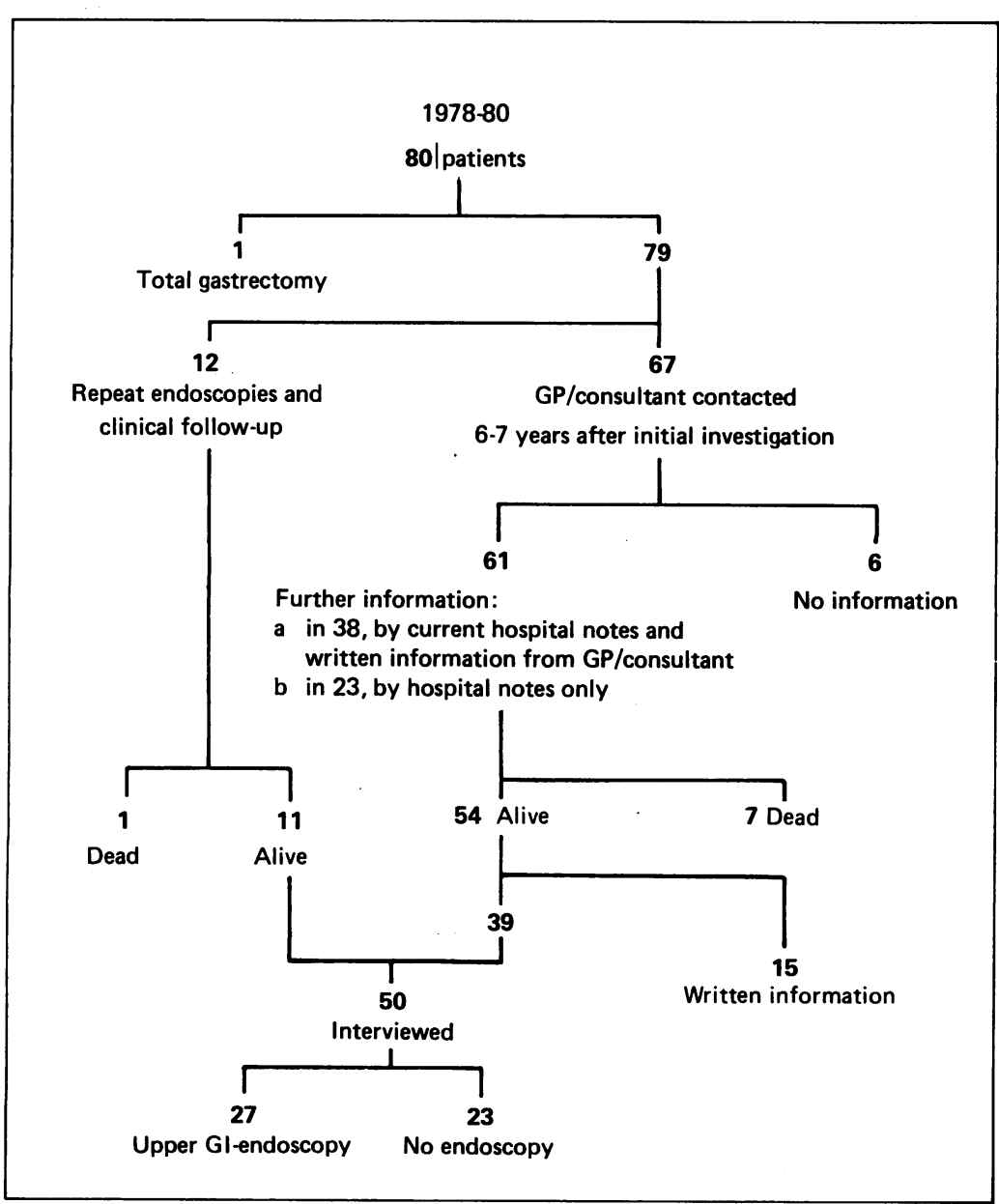

dysplasia in the gastric body at the initial investigation. This polyp was removed and no further adenomas developed during follow up. Another patient (No 37) had shown mild mucosal dysplasia but no polypoid lesions in the initial investigation. Three years later a regenerative prepyloric polyp was seen. The following year an antral adenoma with severe dysplasia was found. As polypectomy was impossible for technical reasons the patient was followed up with multiple biopsies once a year. Finally, continuing growth of the polyp and severe dysplasia at each endoscopy necessitated antrectomy. The resected portion of the distal stomach bore a $1.5 \mathrm{~cm}$ large polypoid lesion with adenomatous hyperplasia and severe dysplasia. No malignant invasion was found. In one patient (No 28) the initial investigation had shown multiple polyps in the gastric body which histological examination showed to be endocrine cell proliferations within the lamina propria (Table I). The polyps did not substantially change in number or size during the observation period. Another patient (No 85) initially had extraepithelial endocrine cell proliferations in the gastric body mucosa. Subsequently, polyps were seen in the body. These polyps comprised clusters and sheets of neuroendocrine cells within the lamina propria, which extended into the submucosa in places. Surprisingly, these polyps, measuring about $5 \mathrm{~mm}$ in diameter, were no longer seen in the following years, although the endocrine cell proliferation within the mucosa and superficial submucosa remained unchanged.

FINAL FOLLOW UP INVESTIGATION (FIGURE 2)

The mean interval between the first investigation and the final study of the overall patient group done in 1985-6 was 6.4 years.

Information was obtained in 73 of 79 patients for the remaining six patients no data were available. Sixty five patients were still alive and eight patients had died since the initial investigation. Of the 65 surviving patients (including 11 from the regular follow up group) information was obtained by interview in 50 and by letter in 15. Twenty seven of the former patients underwent upper gastrointestinal endoscopy after the interview. Biopsy specimens were taken in 26.

The causes of death in the eight patients were: 
TABLE II Site and grade of non-polypous dysplasia in the 26 patients in whom histological examination of biopsy specimens from the gastric body and antrum was carried out at the initial investigation and at the follow up study six to seven years later

\begin{tabular}{|c|c|c|c|c|}
\hline \multirow[b]{2}{*}{ Patient } & \multicolumn{2}{|c|}{$\begin{array}{l}\text { First investigation } \\
(1978-8)\end{array}$} & \multicolumn{2}{|c|}{$\begin{array}{l}\text { Final investigation } \\
(1985-6)\end{array}$} \\
\hline & Antrum & Body & Antrum & Body \\
\hline 10 & 0 & 0 & 0 & 1 \\
\hline 11 & 0 & 0 & 0 & 0 \\
\hline 17 & 0 & 1 & 0 & 1 \\
\hline 23 & 1 & 0 & 0 & 1 \\
\hline & 0 & 1 & 0 & 0 \\
\hline 28 & 0 & 0 & 0 & 1 \\
\hline 31 & 0 & 0 & 0 & 0 \\
\hline 37 & 1 & 1 & 0 & 0 \\
\hline 47 & 0 & 0 & 0 & 1 \\
\hline 50 & 1 & 0 & 1 & 0 \\
\hline 53 & 0 & 2 & 0 & 0 \\
\hline 58 & 1 & 0 & 0 & 0 \\
\hline 60 & 0 & 0 & 0 & 0 \\
\hline & 0 & 0 & 0 & 1 \\
\hline & 1 & 0 & 0 & 0 \\
\hline 69 & 1 & 0 & 0 & 1 \\
\hline 75 & 2 & 0 & 2 & 0 \\
\hline & 0 & 0 & 0 & 0 \\
\hline 79 & 0 & 0 & 0 & 0 \\
\hline 85 & 0 & 0 & 0 & 1 \\
\hline & 0 & 0 & 0 & 1 \\
\hline 90 & 0 & 0 & 0 & 0 \\
\hline 92 & 0 & 0 & 0 & 0 \\
\hline 93 & 0 & 0 & 0 & 0 \\
\hline 103 & 0 & 0 & 0 & 1 \\
\hline 104 & 0 & 0 & 0 & 0 \\
\hline
\end{tabular}

$0=$ no dysplasia, $1=$ mild dysplasia, $2=$ moderate dysplasia .

myocardial infarction (3), leaking aortic aneurysm (1), pulmonary congestion (1), thyroid malignancy (1), and unknown (2).

Clinical follow up. Eight of the 38 patients who were alive and for whom clinical data were available, but who had not been re-endoscoped, suffered from mild gastrointestinal symptoms (such as belching, diarrhoea, heartburn) not suggestive of gastric malignancy. A further patient had constipation, faecal blood loss, and low serum iron. She refused all further investigations recommended to her. Yet another patient had recently undergone surgery for a carcinoma of the descending colon. Of the two patients with severe mucosal dysplasia at the initial investigation, one was a 78 year old woman with coeliac disease and severe arthritis. Two months after the initial investigation her arthritis became active and had to be treated with steroids. She was admitted to hospital on several occasions but upper gastrointestinal symptoms were not reported. She died 10 months after the initial endoscopy. The other patient was a 72 year old man. Biopsy specimens taken at the first endoscopy from the grossly inflamed gastric antrum had shown severe dysplasia. Reinvestigation two months later showed only mild dysplasia in one out of eight biopsy specimens from the same region. During the follow up period he was visited at his home by the research nurse; he had no gastrointestinal symptoms and was perfectly well.

Endoscopic follow up. Of the 27 patients endoscoped - 14 women and 13 men, aged 26 to 81 years (median 57 years) at reinvestigation biopsy specimens were taken in 26 , as mentioned above.

Mucosal dysplasia (Table II). Histological examination showed mild dysplasia in 11 patients and moderate dysplasia in one. In the original study, mild dysplasia had been seen in eight and moderate in two of these patients. None of the patients had developed gastric carcinoma since the initial endoscopy. Thus, the distribution of dysplasia after six to seven years was virtually unchanged (mean dysplasia score $0.46 v 0.50$ ). In the initial study, dysplastic changes were seen more often in biopsy specimens from the gastric antrum. In the final investigation they were found mainly in the body mucosa. Only five patients with dysplasia in the first study also had dysplastic changes at reinvestigation, and in only three was dysplasia found in the corresponding region of the stomach.

Polyps. Polypoid lesions were seen in five of the 27 patients undergoing endoscopy. In one patient the lesion proved to be an adenoma that had newly developed since the initial screening; in another the polypoid lesions seen at endoscopy proved to be gastric microcarcinoids, a repeated finding in this patient. The remaining three patients had regenerative polyps and in two of these a similar type of lesion had already been found at the original investigation.

\section{Discussion}

Our knowledge of the natural history of gastric dysplasia is sparse. This applies also to high risk groups such as patients with chronic atrophic gastritis ${ }^{1-4}$ and those who have undergone partial gastrectomy. ${ }^{19-21}$ Such information is, however, indispensable when it comes to deciding whether or not these patients should be monitored regularly with endoscopy. For this decision, a number of medical and logistical problems have also to be taken into account, since most high risk patients are of advanced age, which makes a cost/benefit analysis difficult. In a 1986 Swedish follow up of pernicious anaemia patients, aimed mainly at early detection of gastric cancer, the cost per diagnosed gastric neoplasia and malignancy was surprisingly low (\$850 and $\$ 1700$, respectively). ${ }^{1014}$

In a recent study by Sjöblom et $a l,{ }^{22}$ gastric carcinomas were detected in 3\% of 196 pernicious anaemia patients of all ages during longterm follow. up (mean 7 years), but gastroscopic screening of 71 patients aged under 75 did not show any more gastric malignancy. In our study, overall mortality during the observation time was eight of $74(11 \%)$. In the six patients with a known cause of death, none was related to pernicious anaemia but four were related to cardiovascular diseases. In the group of patients alive but not resubmitted to endoscopy, there was one confirmed malignancy (which was not of gastric origin) and a further suspected malignancy (in which gastric origin cannot be excluded).

The present follow up study did not show any important overall progression of gastric mucosal dysplasia in 26 patients with pernicious anaemia who were reinvestigated after a period of six to seven years. At the repeat endoscopies (performed at regular intervals) of 12 of these patients, the degree and site of the dysplastic changes fluctuated widely. Screening endoscopies for dysplasia at intervals of less than five years are therefore probably not justified. 
The frequency of polyps in our study was not as high as that reported by Borch et al. ${ }^{23}$ The histological findings varied from one investigation to another. We therefore consider it important to obtain biopsy material from all polypoid lesions in patients with pernicious anaemia, since the differentiation between neoplastic and non-neoplastic lesions cannot be made on the basis of the endoscopic appearance, as has been pointed out previously. ${ }^{9}$

In one patient an interesting observation was made. Multiple polypoid lesions, proved histologically to be mucosal endocrine cell proliferations, developed and then resolved spontaneously during the follow up, although serum gastrin concentrations remained permanently raised - a phenomenon that has recently been described in a case report. ${ }^{24}$

Thus, the clinical value of our examinations was slight in comparison with the effort and patient discomfort involved. One adenomatous polyp with severe dysplasia was detected and removed, however, before malignant transformation could take place.

The reinvestigation of 79 patients with pernicious anaemia illustrates well that follow up studies in patients of this age group are questionable. Compromised health due to concomitant diseases reduces the feasibility of invasive investigations and renders their prophylactic effect doubtful. The rather poor acceptance of endoscopy (only $66 \%$ of the 41 patients to whom it was proposed, agreed) reflects the lack of readiness on the part of elderly people to undergo invasive examinations for preventive purposes.

We conclude that in patients with pernicious anaemia the most probable cause of death seems to be cardiovascular. Regular endoscopic screening for gastric cancer in all such patients is expensive and difficult to organise and the returns in the form of treatable disease detected are slight. These conclusions cannot, however, be extrapolated automatically to other precancerous conditions. In postgastrectomy patients, dysplasia and malignancy may develop and proceed more rapidly, as suggested by the results reported by Offerhaus et al. ${ }^{20}$

In patients with pernicious anaemia we therefore propose that:

(1) All patients should have a detailed gastroscopy with multiple biopsies soon after diagnosis;

(2) Polyps should be removed wherever possible;

(3) Patients with severe mucosal dysplasia or adenomatous polyps, in whom polypectomy is impossible, should be re-examined within a few months in an attempt to rule out the existence of a gastric malignancy;
(4) Patients with no polypoid lesions but with mild to moderate mucosal dysplasia can safely be left without surveillance for about five years, as long as they remain symptom free;

(5) Endoscopic screening is inappropriate in patients who cannot be submitted to surgery unless non-surgical methods of treating gastric cancer, such as laser therapy, become a reality.

1 Siurala $M$, Seppälä $K$. Atrophic gastritis as a possible precursor of gastric carcinoma and pernicious anemia. Acta Med Scand 1960; 173: 455-74.

2 Siurala M, Varis K, Wiljasalo M. Studies in patients with atrophic gastritis: a 10-15-year follow-up. Scand $\mathcal{F}$ Gastroenterol 1966;1:40-8.

3 Siurala M, Lehtola J, Ihamäki T. Atrophic gastritis and its sequelae. Results of 19-23 years' follow-up examinations. Scand $\mathcal{F}$ Gastroenterol 1974; 9: 441-6.

4 Hastrup Svendsen J, Dahl C, Svendsen LB, Christiansen PM. Gastric cancer in achlorhydric patients. A long-term followup study. Scand $\mathcal{F}$ Gastroenterol 1986; 21: 16-20.

5 Elsborg L, Mosbech J. Pernicious anaemia a risk factor for gastric cancer. Acta Med Scand 1979; 206: 315-8.

6 Correa P. Chronic atrophic gastritis as a precursor of cancer. In: Sherlock P, Morson BC, Barbara L, Veronesi V, eds. Precancerous conditions of the gastrointestinal tract. New York: Raven Press, 1983: 145-53.

7 Elsborg L, Andersen D, Myhre-Jensen O, Bastrup-Madsen P. Gastric mucosal polyps in pernicious anaemia. Scand $\dot{\mathcal{F}}$ Gastroenterol 1977; 12: 49-52.

8 Laxen F. Gastric carcinoma and pernicious anaemia in longterm endoscopic follow-up of subjects with gastric polyps. Scand F Gastroenterol 1984; 19: 535-40.

9 Stockbrügger RW, Menon GG, Beilby JOW, Mason RR, Cotton PB. Gastroscopic screening in 80 patients with pernicious anaemia. Gut 1983; 24: 1141-7.

10 Borch K. Epidemiologic, clinicopathologic, and economic aspects of gastroscopic screening of patients with pernicious anaemia. Scand $\mathcal{F}$ Gastroenterol 1986; 21: 21-30.

11 Norcross JW, Monroe SE, Griffin BG. Development of gastric carcinoma in pernicious anemia. Ann Intern Med 1952; 37 338-43.

12 Zamcheck N, Grable E, Ley A, Norman L. Occurrence of gastric cancer among patients with pernicious anemia at the Boston City Hospital. N Engl f Med 1955; 252: 1103-10.

13 Eriksson S, Clase L, Moquist-Olsson I. Pernicious anaemia as a risk factor in gastric cancer. Acta Med Scand 1981; 210 481-4.

14 Borch K, Liedberg G. Prevalence and incidence of pernicious anemia. An evaluation for gastric screening. Scand $\mathcal{f}$ Gastroenterol 1984; 19: 154-60.

15 Rode J, Dhillon AP, Papadaki L, Stockbrügger RW Thompson RJ, Moss E, Cotton PB. Pernicious anaemia and mucosal endocrine cell proliferation of the non-antra stomach. Gut 1986; 27: 789-98.

16 Morson BC, Sobin LH, Grundmann E, Johansen E, Nagayo T, Serck-Hansen A. Precancerous conditions and epithelial dysplasia in the stomach. $\mathcal{F}$ Clin Pathol 1980; 33: 711-21.

17 Morson BC, Jass JR, Sobin LH. Precancerous lesions of the gastrointestinal tract. A histological classification. London, Philadelphia, Toronto: Baillière Tindall, 1985.

18 Hermanek P. Dysplasia in the gastrointestinal tract: definition and clinical significance. Surg Endosc 1987; 1: 5-10.

19 Schrumpf E, Stadaas J, Myren J, Serck-Hanssen A, Aune S Osnes M. Mucosal changes in the gastric stump 20-25 years after partial gastrectomy. Lancet 1977; ii: 467-9.

20 Offerhaus GJA, Huibregtse K, Tytgat GNJ. Endoscopic screening for malignancy in the gastric remnant: The clinical significance of dysplasia in gastric mucosa. $\mathcal{F}$ Clin Patho significance of dysp

21 Viste A, Biörnestad E, Opheim P, et al. Risk of carcinoma following gastric operations for benign disease. Lancet 1986; ii: $502-5$.

22 Sjöblom SM, Sipponen $\mathbf{P}$, Miettinen $M$, Karonen SL, Järvinen HJ. Gastroscopic screening for gastric carcinoids and carcinoma in pernicious anemia. Endoscopy 1988; 20 52-6.

23 Borch K, Renvall H, Liedberg G. Gastric endocrine cell hyperplasia and carcinoid tumors in pernicious anemia. Gastroenterology 1985; 88: 638-48.

24 Harvey RF. Spontaneous resolution of multifocal gastric enterochromaffin-like cell carcinoid tumours. Lancet 1988 ; i: 821 . 